\title{
Residency perception survey among neurosurgery residents in lower-middle-income countries: grassroots evaluation of neurosurgery education
}

\author{
Harsh Deora, MCh, DNB, ${ }^{1}$ Kanwaljeet Garg, $\mathrm{MCh},{ }^{2}$ Manjul Tripathi, $\mathrm{MCh},{ }^{3}$ Shashwat Mishra, $\mathrm{MCh},{ }^{2}$ \\ and Bipin Chaurasia, $\mathrm{MCh}^{4}$
}

1Department of Neurosurgery, National Institute of Mental Health and Neurosciences, Bangalore, Karnataka, India; ${ }^{2}$ Department of Neurosurgery, All India Institute of Medical Sciences, New Delhi, India; ${ }^{3}$ Department of Neurosurgery, Postgraduate Institute of Medical Education and Research, Chandigarh, India; and 4Department of Neurosurgery, Bangladesh State Medical University, Dhaka, Bangladesh

OBJECTIVE The evolution of the neurosurgical specialty in lower-middle-income countries is uniformly a narrative of continuous struggle for recognition and resource allocation. Therefore, it is not surprising that neurosurgical education and residency training in these countries is relatively nascent. Dr. Harvey Cushing in 1901 declared that he would specialize in neurosurgery and gave his greatest contribution to the advancement of neurosurgical education by laying the foundations of a structured residency training program. Similar efforts in lower-middle-income countries have been impeded by economic instability and the lack of well-established medical education paradigms. The authors sought to evaluate the residency programs in these nations by conducting a survey among the biggest stakeholders in these educational programs: the neurosurgical residents.

METHODS A questionnaire addressing various aspects of the residency program from a resident's perspective was prepared with Google Forms and circulated among neurosurgery residents through social media and email groups. Where applicable, a 5-point Likert scale was used to grade the responses to the questions. Responses were collected from May to October 2019 and analyzed using descriptive statistics. Complete anonymity of the respondents was ensured to keep the responses unbiased.

RESULTS A total of 195 responses were received, with 189 of them from lower-middle-income countries (LMICs). The majority of these were from India (75\%), followed by Brazil and Pakistan. An abiding concern among residents was lack of work hour regulations, inadequate exposure to emerging subspecialties, and the need for better hands-on training (> 60\% each). Of the training institutions represented, 89\% were offering more than 500 major neurosurgical surgeries per year, and $40 \%$ of the respondents never got exposure to any subspecialty. The popularity of electronic learning resources was discernible and most residents seemed to be satisfied with the existent system of evaluation. Significant differences $(p<0.05)$ among responses from India compared with those from other countries were found in terms of work hour regulations and subspecialty exposure.

CONCLUSIONS It is prudent that concerned authorities in LMICs recognize and address the deficiencies perceived by neurosurgery residents in their training programs. A determined effort in this direction would be endorsed and assisted by a host of international neurosurgical societies when it is felt that domestic resources may not be adequate. Quality control and close scrutiny of training programs should ensure that the interests of neurosurgical trainees are best served. https://thejns.org/doi/abs/10.3171/2019.12.FOCUS19852

KEYWORDS neurosurgery education; residency; lower-middle-income countries

Neurosurgeons do things that cannot be undone. The grave consequence of our actions renders even the most trivial of tasks difficult. Put a foot wide wooden plank on the driveway and walk its length: no problem. But suspend that same board ten stories in the air and try walking its length again. The difficulty of a task transcends mere mechanics. Irreversibility of our missteps is one reason why I also awaken each morning wondering how I can get out of neurosurgery. The fly struggles on the web.

- Frank T. Vertosick Jr., MD

As is evident from the above anecdote, the importance of sound neurosurgical training cannot be overempha- 
sized. The current generation of neurosurgeons in lowermiddle-income countries (LMICs) ${ }^{18}$ are striving to attain results comparable to those achieved at the best neurosurgical institutions in the world. It is indeed paradoxical that the majority of the neurosurgical burden is shared by LMICs, yet residency positions, infrastructure, and facilities are prohibitively inadequate in these countries. ${ }^{9}$ Most centers for neurosurgical training in these countries are still practicing the Halstedian principles of training, ${ }^{15}$ incorporating the "see one, do one, teach one" approach. With the rapid expansion of the neurosurgical knowledge base and the evolution of surgical procedures and subspecialties, this approach may not be adequate today. What is even more concerning is the fact that most of the training programs in such countries are seldom scrutinized or quality-checked for their adequacy and ability to impart essential neurosurgical training to their trainees. As a result, many of these programs may harbor residents who are apprehensive regarding the potential inadequacies and gaps in their training programs and the need for improvement in specific areas. Neurosurgery is an essential component of healthcare systems but has generally been neglected within global public health, especially within developing countries where communicable diseases have dominated public health concerns. The lack of emphasis on the development of this crucial area of medical practice, despite growing evidence documenting the cost-effectiveness of essential neurosurgical care in LMICs, becomes even more evident when limitations in the essential components of quality neurosurgical education are examined. ${ }^{1}$

The wide variations in neurosurgery education and training in LMICs raise the following questions. What are the exact unmet needs of residents in LMICs? What are the different residency programs and the patterns of certification examinations? What are the available resources, and which of these are the most effective? What resources (human, financial, physical) are required to improve access to neurosurgical education? In this investigation we attempted to answer all of the above questions and to formulate evidence-based suggestions as to what can feasibly be done to improve neurosurgical training in these countries.

\section{Methods}

Based on our similar experience in surveying neurosurgical residents in India, ${ }^{7}$ we developed an online questionnaire using the application Google Forms (Table 1). We circulated the link to the questionnaire among the social media groups of neurosurgery residents belonging to various training programs, primarily targeting LMICs (as defined by the World Bank ${ }^{18}$ ). In order to limit the influence of senior staff or program directors on the survey responses, no official channels of communication were used in the distribution of the survey forms. The respondents were completely anonymized to ensure a free and frank elicitation of the responses. There was no restriction on the number of respondents from each training program. We did not obtain any data detailing personal identifying information (including sex, because this information would make identification of respondents possible owing to the low number of women trainees) apart from the city and the country of their training.

There were a total of 21 major questions in the questionnaire (Table 1), which covered the basic aspects of training, including residency pattern and intensity of training, learning opportunities, academic exposure, residency work profile, subspecialty exposure, learning resource utilization, research time, overall perception of residency, and examination systems. Perceptions about these activities were graded on a 5-point Likert scale, wherever applicable. We asked for responses from candidates who were currently in training or had qualified within the last 5 years. The eventual distribution group was estimated to comprise around 1000 residents. This estimate was arrived at on the basis of the total emails and social media group members where the survey was circulated.

\section{Statistical Analysis}

Most of the observations were analyzed through descriptive statistics, using the statistical programming language R. For comparison of the categorical observations between India and other countries forming the LMIC group, the chi-square test was used. Mean Likert scale scores were compared between groups by using an independent sample t-test.

\section{Results}

\section{Demographics}

We received a total of 189 responses from the respondents of India, Brazil, Pakistan, Ecuador, Nepal, Bhutan, Gaza Strip, Pakistan, and Kazakistan (Fig. 1). The response rate was $19.5 \%$ (195/1000), with the minimum number of responses from low-income countries (only 3 ) and the maximum responses from the lower- and uppermiddle-income nations. We could not get any respondents from China as Google services are restricted there. The respondents from India provided the majority of responses $(74 \%)$. An idea of the heterogeneity of the programs can be gauged from the fact that only $42(22.2 \%)$ respondents had a uniform residency program in their country. There are typically two main avenues of admittance to neurosurgical residencies: either after undergraduate training (e.g., after obtaining the Bachelor of Medicine and Surgery [MBBS] degree) or after completion of a period of training in general surgery (e.g., after obtaining the Master of Surgery, or Magister Chirurgiae [MCh], degree), with the latter system predominating in India. Hence the responses were also indicative of these residency prerequisites, with the majority of the residents opting for the residency programs after a period of training in general surgery (79\%). Typically, a direct entrance after graduation provides neurosurgery training for 6 years with some exposure to general surgery while another program (after 3 years of training in general surgery) includes dedicated neurosurgical training for a 3-year duration.

\section{Residency Pattern}

Most of the respondents were from publicly funded institutions. Only 22/189 responses received were from 
TABLE 1. Questions asked in the survey questionnaire and possible responses allowed

\begin{tabular}{|c|c|}
\hline Questions & Responses Allowed \\
\hline Which country are you from? & All country names \\
\hline $\begin{array}{l}\text { What of the following correctly describes the pattern(s) of residency for neuro- } \\
\text { surgical training being followed in your country? }\end{array}$ & $\begin{array}{l}\text { Multiple types } \\
\text { Single type }\end{array}$ \\
\hline $\begin{array}{l}\text { What of the following describes the shorter version of neurosurgical residency } \\
\text { program allowed in your country? }\end{array}$ & $\begin{array}{l}\text { Entry after general surgery residency } \\
\text { Entry after house job in surgery } \\
\text { Others }\end{array}$ \\
\hline $\begin{array}{l}\text { What of the following describes the longer version of neurosurgical residency } \\
\text { program allowed in your country? }\end{array}$ & $\begin{array}{l}\text { Entry after medical graduation } \\
\text { Others }\end{array}$ \\
\hline What is the status of the medical institution where you are training? & $\begin{array}{l}\text { Government funded } \\
\text { Privately funded/nonfunded }\end{array}$ \\
\hline Date of joining residency & Dates \\
\hline Date of completing residency & Dates \\
\hline $\begin{array}{l}\text { Annual average number of neurosurgical operations performed at your institu- } \\
\text { tion (approximate to the nearest hundred if unsure about the exact figure) }\end{array}$ & Numbers \\
\hline $\begin{array}{l}\text { Do you have any kind of work hour regulations for residents being followed in } \\
\text { your institution? }\end{array}$ & $\begin{array}{l}\text { None } \\
\text { Unofficial } \\
\text { Strict work hour regulations }\end{array}$ \\
\hline Average number of working hrs/wk & $\begin{array}{l}>60 \\
60-80 \\
80-100 \\
>100 \text { hrs }\end{array}$ \\
\hline If you support work hour regulations, in what way will it be useful? & $\begin{array}{l}\text { Improved efficiency } \\
\text { More time for personal life } \\
\text { More research activity possible }\end{array}$ \\
\hline $\begin{array}{l}\text { Perceived relevance of exam activities } \\
\text { Clinical case taking } \\
\text { Seminar } \\
\text { Journal club } \\
\text { Preoperative discussion } \\
\text { Morbidity/mortality } \\
\text { Tumor board } \\
\text { Radiology discussion and interpretation } \\
\text { Didatic lecture }\end{array}$ & $\begin{array}{l}\text { Rating } \\
1 \text { Not relevant at all } \\
2 \text { Somewhat relevant } \\
3 \text { Relevant } \\
4 \text { Very relevant } \\
5 \text { Indispensable }\end{array}$ \\
\hline $\begin{array}{l}\text { Utility of courses } \\
\text { Conferences } \\
\text { Cadaver workshops } \\
\text { Short-term visits } \\
\text { Live surgery workshops } \\
\text { Teaching courses }\end{array}$ & $\begin{array}{l}\text { Rating } \\
1 \text { Not relevant at all } \\
2 \text { Somewhat relevant } \\
3 \text { Relevant } \\
4 \text { Very relevant } \\
5 \text { Indispensable }\end{array}$ \\
\hline $\begin{array}{l}\text { Learning resources utilization } \\
\text { Textbooks } \\
\text { Electronic versions of book } \\
\text { Printed journals } \\
\text { Electronic journals } \\
\text { Wikipedia/Web sources (non-peer reviewed) } \\
\text { Library sources } \\
\text { Youtube/educational videos (e.g., NETS, AllMS) }\end{array}$ & $\begin{array}{l}\text { Rating } \\
1 \text { Not relevant at all } \\
2 \text { Somewhat relevant } \\
3 \text { Relevant } \\
4 \text { Very relevant } \\
5 \text { Indispensable }\end{array}$ \\
\hline $\begin{array}{l}\text { Exposure to subspecialty training and cases } \\
\text { Radiosurgery } \\
\text { Minimally invasive spine surgery } \\
\text { Deformity correction surgery } \\
\text { Epilepsy surgery } \\
\text { Deep brain stimulation } \\
\text { Endovascular approaches }\end{array}$ & $\begin{array}{l}\text { Rating } \\
\text { Inadequate } \\
\text { Adequate } \\
\text { Not available in my program }\end{array}$ \\
\hline
\end{tabular}


» CONTINUED FROM PAGE 3

TABLE 1. Questions asked in the survey questionnaire and possible responses allowed

\begin{tabular}{|c|c|}
\hline Questions & Responses Allowed \\
\hline $\begin{array}{l}\text { Relevance of pattern of examination } \\
\text { Theory } \\
\text { Clinical case presentation } \\
\text { Case scenarios } \\
\text { Live surgical demonstration } \\
\text { Imaging interpretation }\end{array}$ & $\begin{array}{l}\text { Rating } \\
\text { Can't say } \\
\text { Extremely relevant } \\
\text { Irrelevant } \\
\text { Not applicable }\end{array}$ \\
\hline Total number of cases operated on per year at your center & $\begin{array}{l}<500 \text { per year } \\
\geq 500 \text { per year }\end{array}$ \\
\hline $\begin{array}{l}\text { Do you believe that general surgery training is relevant during training for } \\
\text { neurosurgery? }\end{array}$ & $\begin{array}{l}\text { Rating } \\
1 \text { Not relevant at all } \\
2 \text { Somewhat relevant } \\
3 \text { Relevant } \\
4 \text { Very relevant } \\
5 \text { Indispensable }\end{array}$ \\
\hline How do you rate the quality of surgical exposure in your training program? & $\begin{array}{l}\text { Rating } \\
1 \text { Very poor } \\
2 \text { Poor } \\
3 \text { Average } \\
4 \text { Good } \\
5 \text { Excellent }\end{array}$ \\
\hline How do you rate your own hands-on experience in surgery during your training? & $\begin{array}{l}\text { Rating } \\
1 \text { Very poor } \\
2 \text { Poor } \\
3 \text { Average } \\
4 \text { Good } \\
5 \text { Excellent }\end{array}$ \\
\hline Who is your primary teacher during such sessions of hands on training? & $\begin{array}{l}\text { Choose one } \\
1 \text { Resident senior to me in the program } \\
2 \text { Junior faculty member } \\
3 \text { Senior faculty member } \\
4 \text { Unsupervised }\end{array}$ \\
\hline
\end{tabular}

AlIMS = All India Institute of Medical Sciences; NETS = Neurosurgery Education and Training School.

trainees working in privately funded institutions. Almost all (187/189) of the respondents were either in residency training or had completed their residency less than 5 years earlier (Fig. 2).

Eighty-nine percent (170 responses) of the surveyed institutes were high-volume centers (arbitrarily defined as centers performing more than 500 major operative neurosurgery procedures per year), while only $11 \%$ were low volume, the majority from Brazil, Columbia, and Pakistan. Most of the respondents agreed that training in general surgery may be beneficial for further neurosurgery training, as only $27(14 \%)$ respondents rated it less than 3 on a 5-point Likert scale. Only 45/189 (23\%) respondents had strict work hour regulations, the majority being from Brazil, Columbia, and Romania (25/45). However, despite the low prevalence of work hour regulations, only 22 (13\%) respondents rated its desirability as less than 3 on a 5-point Likert scale. Most respondents believed that work hour restrictions would improve performance efficacy (67 respondents), increase research opportunities (60 respondents), and allow more time for personal life (40 respon- dents). Respondents reported a wide variation in average work hours per week, ranging from less than 60 working hours per week (2/189) to more than 100 hours per week $(55 / 189)$. The majority of the residents reported working more than 80 hours per week, with 55 (29\%) working for more than 100 hours per week and 64 (34\%) working between 80 and 100 hours per week.

\section{Training Programs}

Most of the academic programs comprised grossly similar education patterns (Fig. 3) (such as clinical case discussions, preoperative sessions, radiology meetings, tumor boards, journal clubs, seminars, didactic lectures, and morbidity and mortality meetings) with subtle variability in their execution per the local practices. We queried for the perceived relevance of these components of the academic schedule among residents. Clinical case presentation was uniformly favored, with $91 \%$ of respondents grading it as highly relevant ( $>$ grade 2 response). Presentation of seminars $(90 \%)$ and journal club (journal article presentation) (84\%) (> grade 2 response) are regu- 


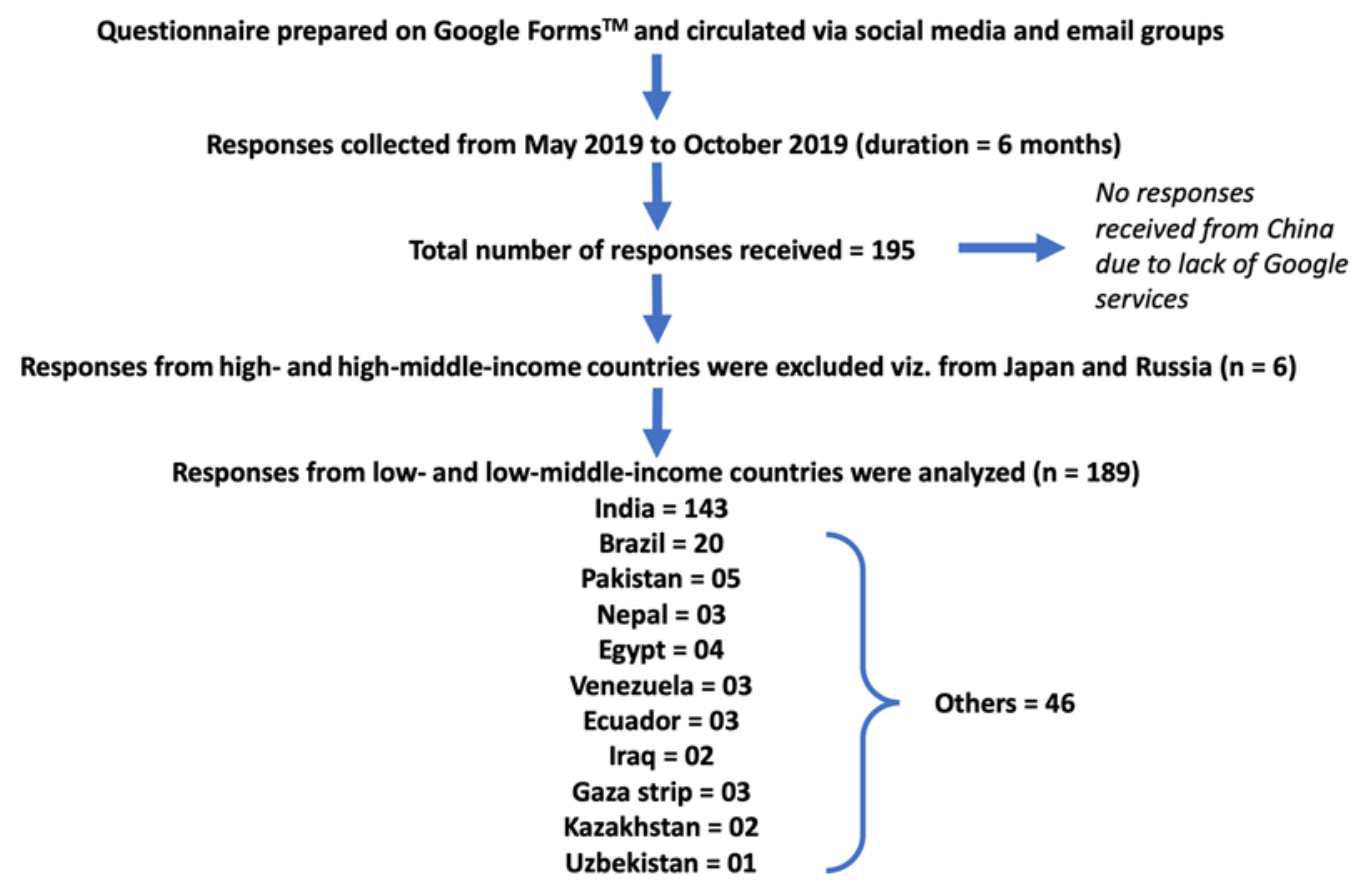

FIG. 1. Methodology of conduct of survey and analysis of responses.

lar features of most neurosurgical centers. More than $95 \%$ of the residents considered the preoperative discussion as the most useful activity of the academic schedule, with $76 \%$ of respondents marking it as indispensable. Mortality/morbidity conferences met the teaching expectations $(86 \%)$ of the residents. However, tumor boards $(18 \%)$ and didactic lectures (15\%) were found to be less useful than we expected. The radiology conference discussions were assessed as slightly better (84\%) and earned a higher (45\%) grade 5 response.

One of the crucial components of residency training is the opportunity to attend academic conferences, workshops, and continuing medical education (CME) programs. Not only do these activities help to broaden one's outlook but also provide opportunities for unsupervised interaction among trainees and educators drawn from diverse backgrounds, perceptively leading to better insight into the topic of interest. Interestingly, the respondents considered cadaver courses and live surgery workshops most useful (Fig. 4) but did not have a high opinion of conferences and short-term visits to other hospitals.

\section{Subspecialty Exposure}

Exposure to upcoming and established neurosurgical subspecialties was an issue of disquiet among the respondents. About a third of the residents reported having training experience in radiosurgery $(36 \%)$ and minimally invasive spine surgery (31\%) (Fig. 5). The majority of the residents felt their training was deficient in deformity correction (80\%) and deep brain stimulation (19\%) surgeries. Overall, residents felt content and confident with their routine neurosurgery training, yet they were dissatisfied with subspecialty exposure. The need for further subspecialty training through dedicated fellowships is evident from the fact that up to $40 \%$ of respondents did not report substantial residency experience in any of the queried subspecialties.

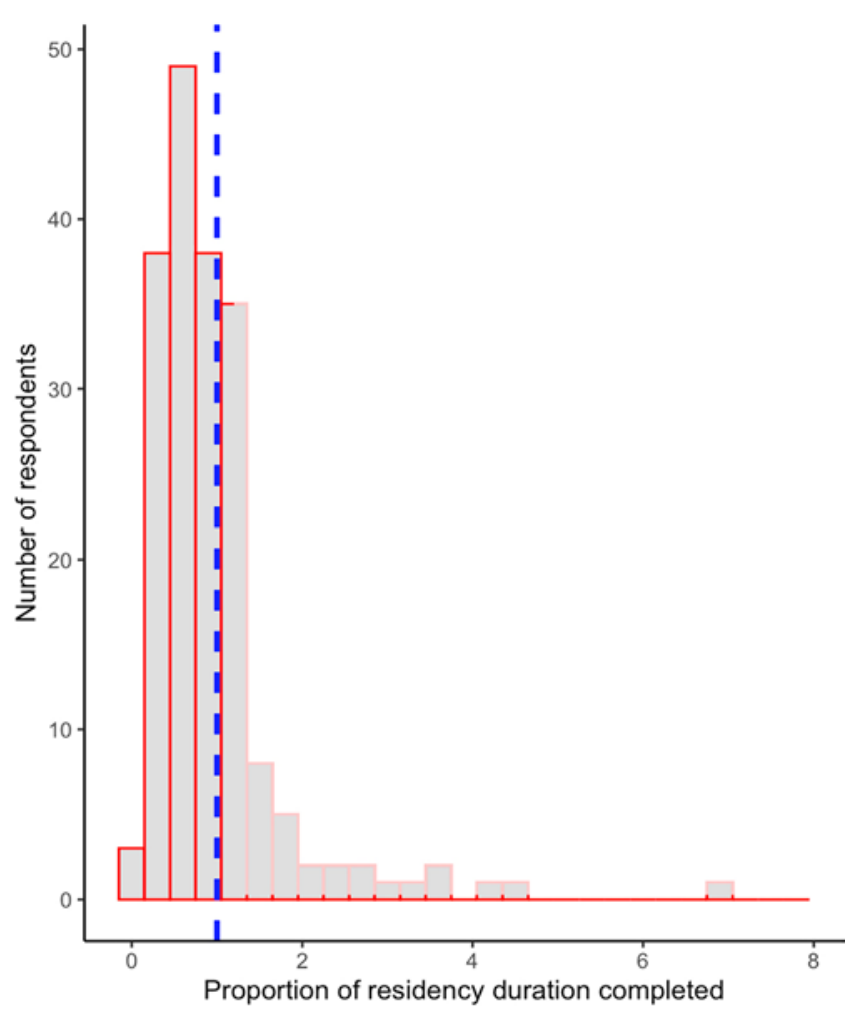

FIG. 2. Distribution of respondents across residency training period (dashed vertical line represents residency completion). 


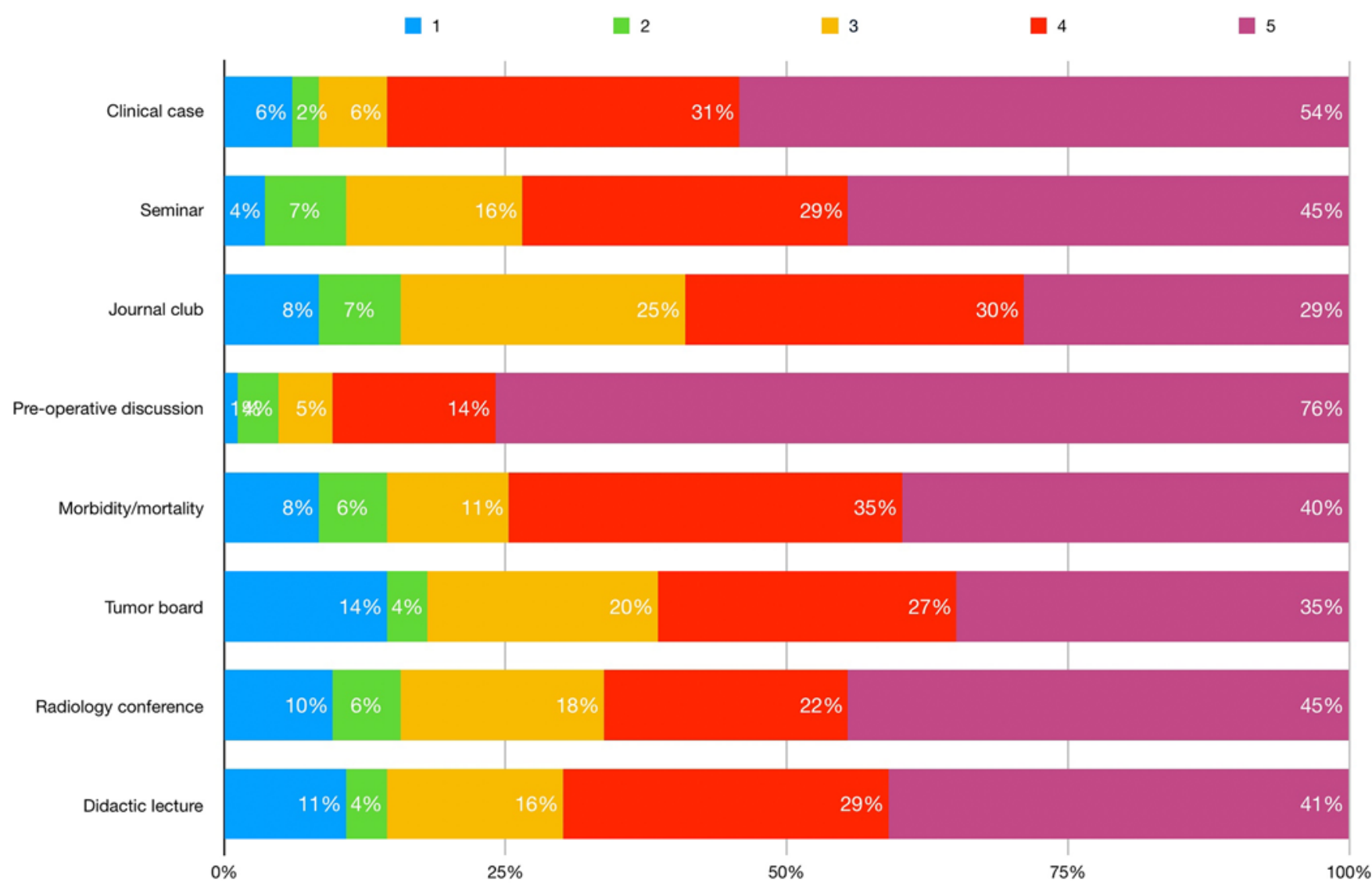

FIG. 3. Perceived relevance of examination and teaching activities on a scale of $1-5$, with 5 being extremely relevant.

\section{Examination Patterns and Learning Resources}

An interesting finding was the heavy dependence on electronic sources, with $77 \%$ of respondents relying on electronic textbooks and journals as their primary educational material (Fig. 6, upper panel). Instructively, the traditional tools of study such as library references and printed copies of journals seem to be becoming less popular among the respondents. Only $10 \%$ and $18 \%$ of residents admitted referring to library books and the printed copy of journals, respectively, for their queries. The reasons for

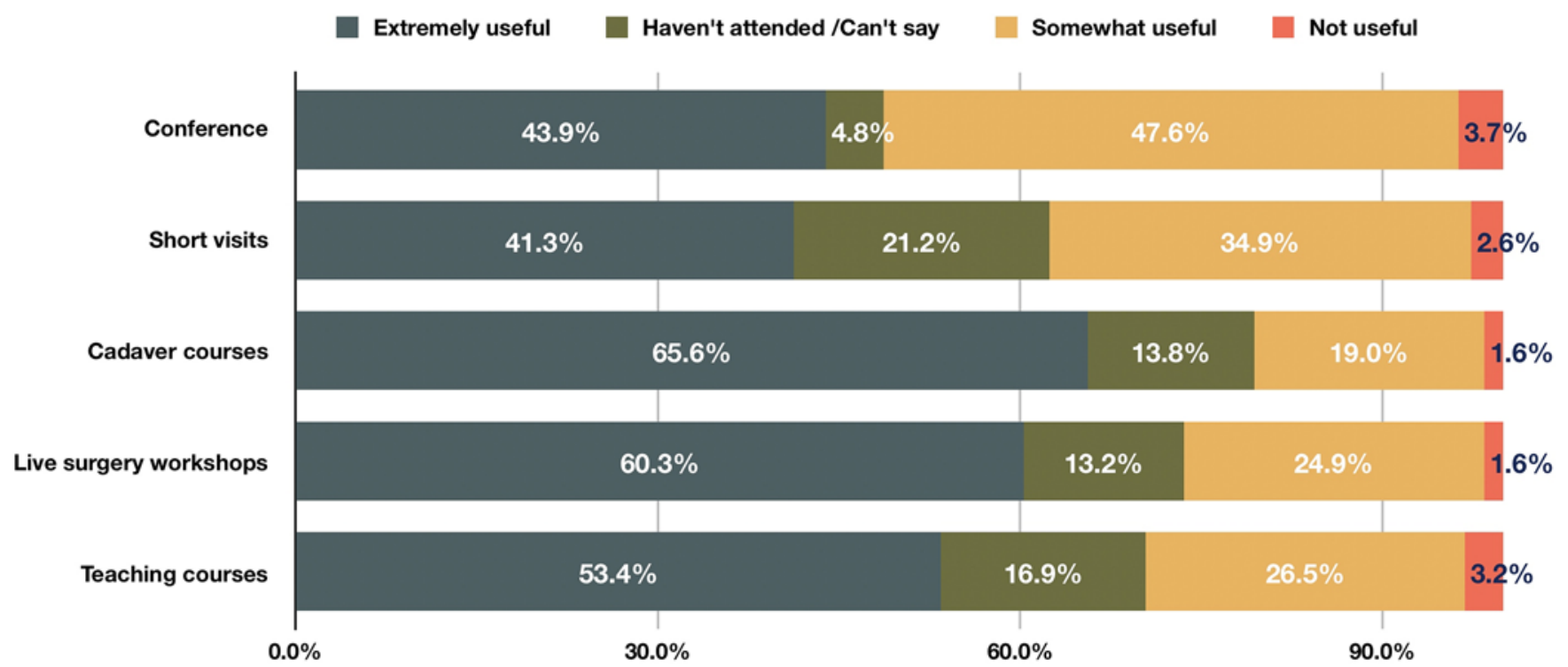

FIG. 4. Perceived utility of ancillary training opportunities. 


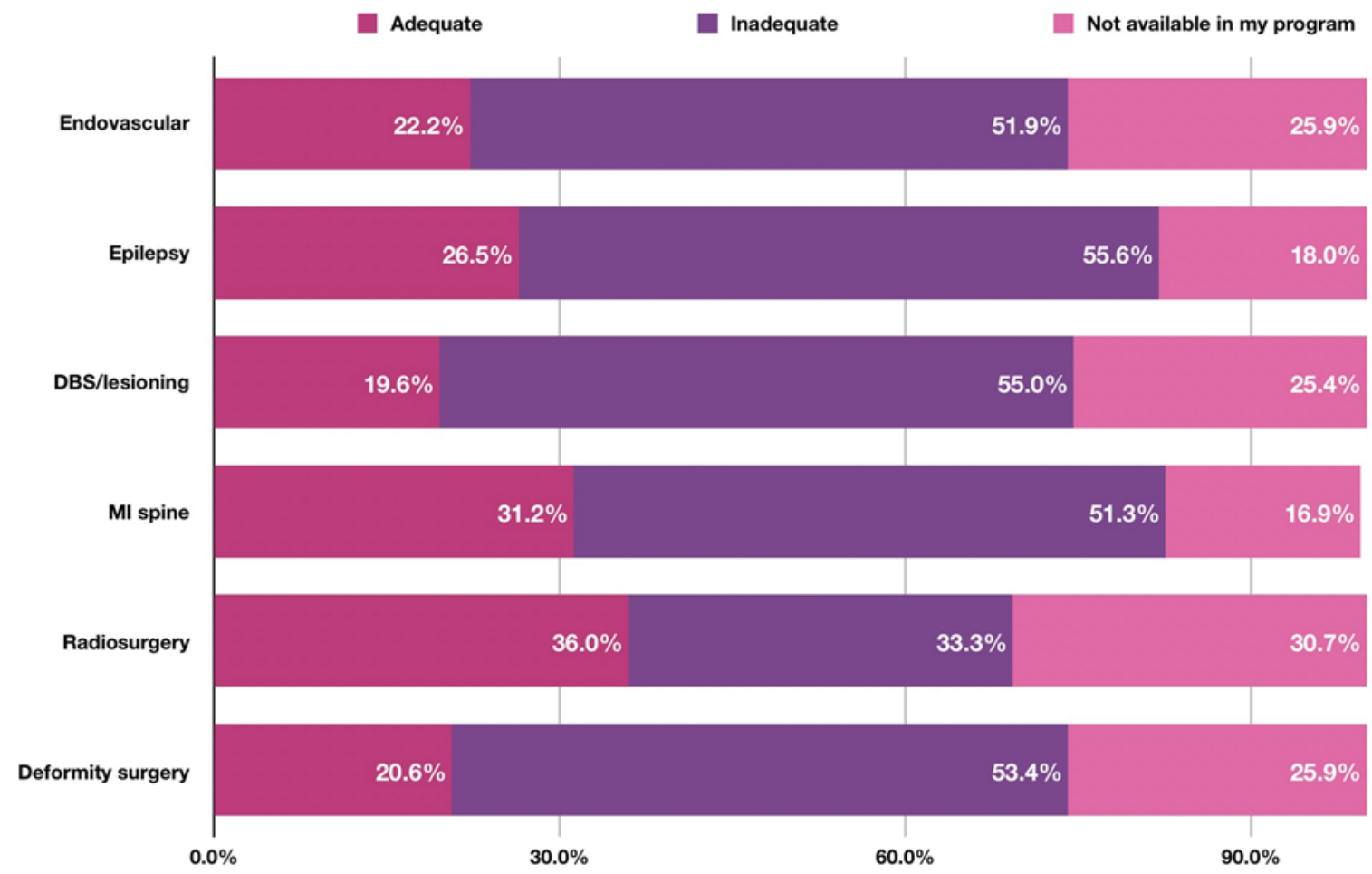

FIG. 5. Exposure of residents to subspecialty training in LMICs. DBS = deep brain stimulation; MI = minimally invasive.

the same are not difficult to find, with electronic resources carrying the advantages of ubiquitous availability over the internet and ease of mobility. In addition, $33 \%$ of residents also relied on non-peer-reviewed sources like Wikipedia or other websites. Thus, it may be worthwhile for the neurosurgical community to contribute toward maintaining the accuracy of information being displayed by these websites.

Examination patterns may also differ among residency programs, but most of the residents seemed to be satisfied with the current pattern of examination, with $89 \%$ of respondents considering their examination pattern satisfactory enough to judge their clinical and surgical acumen. With regard to their utility in their future practice, respondents ranked clinical case presentations, practical surgical demonstrations, and radiology interpretation high among the modalities for trainee assessment (Fig. 6, lower panel). Tests using hypothetical case scenarios and emphasis on theory were poorly received.

\section{Surgical Exposure and Training}

Quality of surgical exposure was considered good by residents at most of the centers, with only $10 \%$ of the respondents unsatisfied (rating it below a grade 2 response on the Likert scale). Sixteen percent of the respondents reported poor exposure to operative experience and handson opportunities. Senior colleagues were the most frequent supervising authorities (45\%) in the operating room, when trainees were doing procedures independently. Only $24 \%$ of the respondents reported being watched by senior faculty while operating.

\section{India Versus Other Countries}

Since the majority of the responses were from India it was prudent to compare the responses of resident from India with those from other countries (Table 2). The results were remarkable only with respect to work hour regulation and subspecialty exposure. Work hour regulations were either enforced $(45.6 \%)$ or observed unofficially $(19.6 \%)$ in the "other" group. In comparison to "other" nations, exposure to certain subspecialties and their availability was also significantly deficient $(\mathrm{p}<0.01)$ in India (except for deep brain stimulation surgery).

\section{Discussion}

The experiences and expectations of the respondents in residency programs from LMICs may be different from those of neurosurgery residents in residency programs in the high-income, more-developed countries, which are rigorously monitored with feedback commissioned independently from both the instructors and trainees by a central authority. ${ }^{10}$ The Accreditation Council of Graduate Medical Education is a nonprofit private organization that oversees residency programs in the United States. An analogous system has not evolved so far in LMICs, possibly due to lack of initiative and the presence of logistical difficulties in coordinating data acquisition from different residency programs in the absence of a centralized registry. ${ }^{1}$

To address these deficiencies of data coordination in LMICs, some organizations have contributed by voluntarily providing training in already established hospitals and institutes, such as the College of Surgeons of East, 


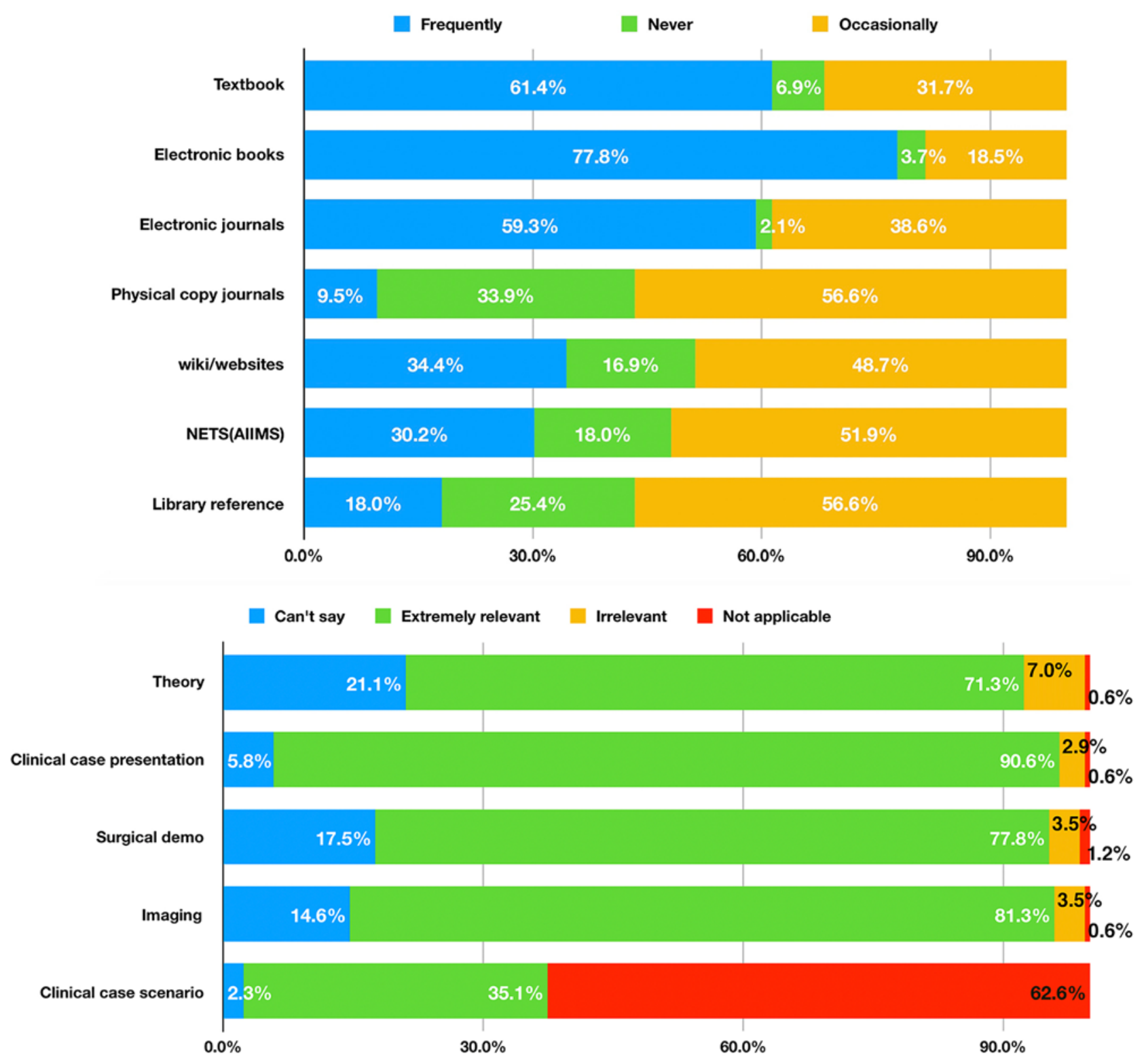

FIG. 6. Upper: Chart representing utilization of learning resources among LMIC neurosurgical residents. AlIMS = All India Institute of Medical Sciences; NETS = Neurosurgery Education and Training School. Lower: Chart showing the perceived relevance of various components of a neurosurgery exit exam.

Central and Southern Africa (COSECSA) and the Foundation for International Education in Neurological Surgery (FIENS). 4,5

The global initiative Africa 100 was pioneered by Professor Majid Samii and was designed to increase the number of permanent practicing surgeons on the continent. ${ }^{3}$ There has also been an increase in the number of SouthSouth partnerships promoting the exchange of resources, technology, and knowledge between developing countries, exemplified by a large number of neurosurgeons practicing in Nepal after being trained in India. Under the aegis of the World Federation of Neurosurgical Societies (WFNS), many neurosurgeons in South Asia have undergone longand short-term training and fellowships in various subspecialties of neurosurgery in other countries, including Tur- key, India, and China. Japan has tremendously supported all aspects of neurosurgical education (training, fellowships, scholarships, seminars, workshops, and instrumentation support) for Bangladesh. Young neurosurgeons have benefitted from this assistance, which has had a salutary effect on outcomes of neurosurgery in their native country. The WFNS has thus contributed immensely to establish educational paradigms that incorporate open-access, webbased educational platforms accessible to trainees and consultants from all corners of the globe. ${ }^{11}$

We do acknowledge that ours might be the first article of its kind in providing feedback on neurosurgical training in LMICs from the perspective of the neurosurgery resident. We certainly do not intend to modify or provide suggestions to change the neurosurgical curriculum of any 
TABLE 2. Areas of significant difference among responses from India versus other countries

\begin{tabular}{|c|c|c|c|c|c|c|c|}
\hline Area of Significant Difference & \multicolumn{3}{|c|}{ India ( $n=143$ responses) } & \multicolumn{3}{|c|}{ Others ( $\mathrm{n}=46$ responses) } & \multirow{2}{*}{$\begin{array}{r}p \text { Value } \\
0.003\end{array}$} \\
\hline Work hour regulation & & & & & & & \\
\hline None & & $80(55.9)$ & & & $16(34.8)$ & & \\
\hline Strict official & & $24(16.7)$ & & & $21(45.6)$ & & \\
\hline Unofficial & & $39(27.2)$ & & & $9(19.6)$ & & \\
\hline Subspeciality exposure & Adequate & Inadequate & Not Available & Adequate & Inadequate & Not Available & \\
\hline Stereotactic radiosurgery & $61(42.7)$ & $50(35)$ & $32(22.4)$ & 7 (15.2) & $13(28.3)$ & $26(56.5)$ & $<0.001$ \\
\hline Endovascular surgery & $23(16)$ & $83(58)$ & $37(25.9)$ & $19(41)$ & $15(32.6)$ & $12(26)$ & $<0.001$ \\
\hline Epilepsy surgery & $43(30.1)$ & $84(58.7)$ & $16(11.2)$ & $7(15.2)$ & $21(45.7)$ & $18(39.1)$ & $<0.001$ \\
\hline Deep brain stimulation & $27(18.9)$ & $85(59.4)$ & $31(21.7)$ & $10(21.7)$ & $19(41.3)$ & $17(37)$ & 0.06 \\
\hline Minimally invasive spine surgery & $38(26.5)$ & $85(59.4)$ & $19(13.3)$ & $21(45.7)$ & $12(26.1)$ & $13(28.3)$ & $<0.001$ \\
\hline Spinal deformity surgery & $22(15.4)$ & $86(60)$ & $35(24.5)$ & $17(37)$ & $15(32.6)$ & $14(30.4)$ & 0.001 \\
\hline
\end{tabular}

Values are presented as number of responses (\%) unless otherwise indicated.

of these countries. The advancement of a discipline as complex as neurosurgery cannot happen quickly, and the developed world has had a significantly longer dalliance with neurosurgical procedures. William Macewen performed the first successful brain tumor removal in 1879 after locating it by clinical methods. ${ }^{14,16} \mathrm{~A}$ few years later, Harvey Cushing announced his intention of specializing in neurosurgery. Around this time, the LMICs were still occupied with the more pressing challenges of addressing malnutrition and containing communicable diseases as public health priorities.

In an effort to narrow this yawning gap, the training programs in LMICs have only recently included the development of infrastructure, capacity building, cadaveric workshops, better surgical exposure, logbook maintenance, and better surgical oversight.

Most of the surveyed residents reported working for long hours. Only 2/189 residents worked for less than a 60hour week. Thirty-five percent of the respondents in our survey reported exceeding 100 hours at work in a week. In contrast, the European Working Time Directive (EWTD) ${ }^{2}$ restricts the working hours from an average of 56 per week to 48 per week for residents. The 2016 guidelines of the Accreditation Council for Graduate Medical Education for residency programs recommend against trainees exceeding 80 working hours per week.

Despite working long hours, the surveyed residents were dissatisfied with their operative training and handson exposure. This finding seems to indicate that substantial training time is being spent on activities which are not directly contributory to neurosurgical education. With ancillary staff being nonexistent or scarce in most of the hospitals in LMICs, it is not uncommon for the residents to mandatorily subsume administrative and logistical responsibilities, leaving little time for core neurosurgical training. This is especially true for departments heavily burdened with neurotrauma emergencies. Hence, work hour metrics may not be reflective of the actual training time available. It is necessary therefore to assess these training programs by more representative parameters such the logbook records, number of cases handled independently, etc.

One of the concerning findings of the survey is the lack of adequate subspecialty exposure among residents, especially in India, where the situation is acute. Forty percent of the respondents never got exposure to any subspecialty. The field of neurosurgery has witnessed an ongoing change in its different substreams due to increasing expertise, need for less-invasive surgical methods/technologies, and vaulting expectations of both patients and caregivers. A subspecialty is not a mere luxury, even in the setting of limited resources, and carries an indispensable role in the global neurosurgical perspective. If the neurosurgical subspecialties are not sufficiently promoted, millions of people in poor countries with limited access to surgical care will continue to endure more morbid methods of treatment with suboptimal outcomes. Perhaps better exposure during residency, encouragement of resident exchange with reputed centers of excellence in neurosurgical subspecialties, and development of low-cost utilitarian equipment may ensure early adoption of refined and more effective treatment practices.

On a positive note, most residents acknowledged the importance of preoperative discussion and various other academic activities such as seminars and journal clubs. The institutions providing training to neurosurgeons should continue such academic exercises with more fervent participation both at the resident and faculty levels. The difficult task of providing routine care under limited resources sometimes shrinks the opportunities to attend academic activities organized on a wider platform, such as conferences and workshops. Electronic sources of current information have become substitutes for the traditional methods of attaining knowledge. The convenience of access to these electronic media and their low cost make them a popular choice among residents for reading and referencing in the moments between their hectic training activities. Accordingly, investment in expanding the reach and content of electronic media is expected to yield better learning outcomes for academic institutions.

The incorporation of better hands-on surgical exposure and frequent practice in subspecialty training/cadaveric courses are the need of the hour, with overwhelming numbers of residents being in favor of the same. ${ }^{8}$ This finding may stem from the fact that most of the training time in 
these nations is commandeered by neurotrauma and nontrauma emergencies. Exposure to nonemergent surgical care is limited to some specific centers only. The WHO established a Global Initiative on Emergency and Essential Surgical Care (GIESSC) to address the same issue. ${ }^{6}$ The WHO Integrated Management of Emergency and Essential Surgical Care Toolkit includes training and research for surgical services at district hospitals. ${ }^{17}$ Large case burden, attractive cost-effectiveness, and neglect in the past have transformed this area into a potential priority investment for the world's needy.

\section{Study Limitations}

One of the obvious limitations of this type of reporting is sampling bias. Since the responses were completely anonymized we could not determine whether major training programs were proportionately represented. Independent verification of information reported by respondents was not feasible in the questionnaire-based study design. With $75 \%$ of the response being from India, the survey is skewed in its favor. The LMICs of the South East Asian region are inadequately represented, as the population of India is many times greater in number than the populations of all the other countries put together. The situations in most of the LMICs are similar, ${ }^{12,13,19}$ and hence conclusions drawn from the Indian scenario may be relevant to the entire Asian population. Several other questions could have also been asked that are relevant to the topic of interest, neurosurgery education, such as opportunities for research and audit projects and the use of simulation in training. As such, the current survey took almost 6 minutes to complete and from our previous experience longer surveys result in poor response rates. ${ }^{7}$ The reach of the survey and the received responses were limited, and that has resulted in the omission of some regions completely. The idea was initially to cover all low- and middle-income countries. Although the link to the survey was circulated among accessible social media groups, however, this goal was not realized in the results because the response rate was poor. Nevertheless, the survey still revealed important information and highlighted areas of concern.

\section{Conclusions}

"The axe forgets, but the tree remembers." Neurosurgeons carry onerous responsibilities on their shoulders when surgically treating the disorders of the central nervous system. Neurosurgical care is no longer only a desirable aspect but is indispensable for addressing the global surgical burden. Inadequate exposure to subspecialties, exhausting working hours with poorly distributed training time, and inconsistent supervision are some of the challenges that residents in LMIC are facing. Electronic resources, with access facilitated by the expanding reach of the internet, are heavily favored by the trainees. This trend has tremendously increased the scope for a more productive collaboration between international neurosurgical societies and the training programs in LMICs through substantive exchange of training material, which can potentially ameliorate the perceived deficiencies in the training experience.

\section{References}

1. Banerji AK: Neurosurgical training and evaluation-need for a paradigm shift. Neurol India 64:1119-1124, 2016

2. British Medical Association. What Is the European Working Time Directive? London: BMA (https://www.bma. org.uk/advice/employment/working-hours/ewtd) [Accessed January 14, 2020]

3. Budohoski KP, Ngerageza JG, Austard B, Fuller A, Galler R, Haglund M, et al: Neurosurgery in East Africa: innovations. World Neurosurg 113:436-452, 2018

4. Dempsey KE, Qureshi MM, Ondoma SM, Dempsey RJ: Effect of geopolitical forces on neurosurgical training in subSaharan Africa. World Neurosurg 101:196-202, 2017

5. Dempsey RJ, Nakaji P: Foundation for International Education in Neurological Surgery (FIENS) global health and neurosurgical volunteerism. Neurosurgery 73:10701071,2013

6. Dewan MC, Rattani A, Fieggen G, Arraez MA, Servadei F, Boop FA, et al: Global neurosurgery: the current capacity and deficit in the provision of essential neurosurgical care. $\mathbf{J}$ Neurosurg 130:1055-1064, 2019

7. Garg K, Deora H, Mishra S, Tripathi M, Sadashiva N, Chandra PS, et al: How is neurosurgical residency in India? Results of an anonymized national survey of residents. Neurol India 67:777-782, 2019

8. Gasco J, Holbrook TJ, Patel A, Smith A, Paulson D, Muns A, et al: Neurosurgery simulation in residency training: feasibility, cost, and educational benefit. Neurosurgery 73 (Suppl 1):39-45, 2013

9. Jamison DT, Breman JG, Measham AR, Alleyne G, Claeson M, Evans DB, et al (eds): Disease Control Priorities in Developing Countries, ed 2. Washington, DC: World Bank, 2006 (http://www.ncbi.nlm.nih.gov/books/NBK11728/) [Accessed January 14, 2020]

10. Kang D, Siddiqui S, Weiss H, Sifri Z, Krishnaswami $\mathrm{S}$, Nwomeh B, et al: Are we meeting ACGME core competencies? A systematic review of literature on international surgical rotations. Am J Surg 216:782-786, 2018

11. Karekezi C, El Khamlichi A: Takeoff of African neurosurgery and the World Federation of Neurosurgical Societies Rabat Training Center alumni. World Neurosurg 126:576-580, 2019

12. Karras CL, Tran HM, Dornbos D III, Nguyen P, Nimjee SM, Prevedello DM, et al: Inside Vietnam's largest neurosurgery department. World Neurosurg 105:122-125, 2017

13. Khan AH, Hossain AM, Shalike N, Barua KK: Evolution of neurosurgery in Bangladesh. Bangladesh J Neurosurg 8:57-62, 2019

14. Kirkpatrick DB: The first primary brain-tumor operation. J Neurosurg 61:809-813, 1984

15. Kotsis SV, Chung KC: Application of the "see one, do one, teach one" concept in surgical training. Plast Reconstr Surg 131:1194-1201, 2013

16. Preul MC: History of brain tumor surgery. Neurosurg Focus 18(4):Introduction, 2005

17. Spiegel DA, Abdullah F, Price RR, Gosselin RA, Bickler SW: World Health Organization Global Initiative for Emergency and Essential Surgical Care: 2011 and beyond. World J Surg 37:1462-1469, 2013

18. World Bank. World Bank Country and Lending Groups. Washington, DC: World Bank (https://datahelpdesk. worldbank.org/knowledgebase/articles/906519-world-bankcountry-and-lending-groups) [Accessed January 14, 2020]

19. Xu T, Evins AI, Lin N, Chang J, Hu G, Hou L, et al: Neurosurgical postgraduate training in China: moving toward a national training standard. World Neurosurg 96:410-416, 2016 


\section{Disclosures}

The authors report no conflict of interest concerning the materials or methods used in this study or the findings specified in this paper.

\section{Author Contributions}

Conception and design: Mishra, Deora, Tripathi. Acquisition of data: Deora, Tripathi. Analysis and interpretation of data: Mishra, Deora, Tripathi. Drafting the article: Mishra, Deora, Tripathi. Critically revising the article: Mishra, Deora, Garg. Reviewed submitted version of manuscript: Mishra, Deora, Garg, Chaurasia. Approved the final version of the manuscript on behalf of all authors: Mishra. Statistical analysis: Mishra, Deora, Garg. Administrative/technical/material support: Deora, Garg. Study supervision: Deora, Garg.

\section{Supplemental Information}

Current Affiliations

Dr. Manjul Tripathi: National Institute for Health Research Group on Neurotrauma, University of Cambridge, United Kingdom.

\section{Correspondence}

Shashwat Mishra: All India Institute of Medical Sciences, New Delhi, India.smishra@aiims.edu. 